\title{
Patient perceptions of pharmacist roles in guiding self-medication of over-the-counter therapy in Qatar
}

This article was published in the following Dove Press journal:

Patient Preference and Adherence

II April 2010

Number of times this article has been viewed

\author{
Kerry Wilbur' \\ Samah El Salam' \\ Ebrahim Mohammadi ${ }^{2}$ \\ 'Qatar University College \\ of Pharmacy, Doha, Qatar; ${ }^{2}$ Qatar \\ Petroleum Medical Services, \\ Doha, Qatar
}

Correspondence: Kerry Wilbur College of Pharmacy, Qatar University, PO Box 27I3, Doha, Qatar

Tel +974485 I $941 / 7$

Fax+974 4930449

Email kwilbur@qu.edu.qa
Background: Self-care, including self-medication with over-the-counter (OTC) drugs, facilitates the public's increased willingness to assume greater responsibility for their own health. Direct consultation with pharmacists provides efficient professional guidance for safe and appropriate OTC use.

Objective: The purpose of this study was to characterize patient perceptions of pharmacists and use of nonprescription therapy in an ambulatory care population in Qatar.

Methods: Patients having prescriptions filled at one organization's private medical clinics during two distinct two-week periods were invited to participate in a short verbal questionnaire. Awareness of pharmacist roles in guiding OTC drug selection was assessed, as were patient preferences for OTC indications. Attitudes towards pharmacist and nurse drug knowledge and comfort with direct dispensing were also evaluated.

Results: Five hundred seventy patients participated representing 29 countries. Most respondents were men $(92.1 \%)$ with mean age of 38.3 years. Almost 1 in 7 did not know medical complaints could be assessed by a pharmacist (15.3\%) and 1 in $5(21.9 \%)$ were unaware pharmacists could directly supply OTC therapy. The majority (85.3\%) would be interested in this service. In general, respondents were more comfortable with medication and related advice supplied by pharmacists as opposed to nursing professionals.

Conclusion: Patients were familiar with the roles of pharmacists as they pertain to selfmedication with OTC therapy and described the desire to use such a service within this Qatar ambulatory health care setting.

Keywords: patient, self-medication, over-the-counter, pharmacist, Qatar

\section{Introduction}

The majority of drug therapy in Qatar is available without a prescription. With the exception of antibiotics, anabolic steroids, narcotic, and controlled drugs, patients may self-select all other medications without a physician-visit. This broad availability of drugs without a prescription is similarly found in other countries in the Gulf, Central America, parts of Eastern Europe, and Asia. ${ }^{1-3}$ While self-care may facilitate the public's increased willingness to assume greater responsibility for their own health, unsupervised patient self-medication places patients at risk for medication misuse. Individuals must be able to recognize the symptoms or disorder they wish to treat (or prevent), choose an appropriate product, follow the directions for use on the label, and monitor for desired outcomes and adverse effects. ${ }^{4,5}$ Patient self-medication may also unwittingly generate dangerous drug-drug and drug-disease interactions. 
The wide range of nonprescription medicines in Qatar highlights the need for professional guidance. ${ }^{6}$ Pharmacists play a valuable role in identifying, solving, and preventing drug-related problems (DRPs) for the purpose of achieving optimal patient outcomes and quality of life. Ambulatorybased pharmacists have the opportunity and responsibility to foster safe, appropriate, effective, and economical use of all medications, especially those therapies patients are self-selecting. Pharmacists are uniquely trained to assist patients in the selection of appropriate drug therapy and the circumstances under which a physician should be consulted before patients embark upon independent self-care. ${ }^{7}$

Qatar Petroleum (QP) is the largest private employer in Qatar. Comprehensive medical care is provided to employees, subcontractors, and their families (Qatari and non-Qatari) at four QP medical clinics and associated QP clinic pharmacies throughout Qatar. However, unlike pharmacies elsewhere in the country, all medications provided to patients in this health care setting must be prescribed by a physician. Health care providers in this organization have recognized that this system is associated with unnecessary medical office visits and potential overtreatment of many benign or self-limiting clinical conditions with unnecessary and more expensive therapies. ${ }^{8}$ As such, a collaborative drug therapy management model was developed by pharmacists and physicians at QP whereby pharmacists are preauthorized to directly provide/prescribe 'over-the-counter' (OTC) medications from a predetermined list of therapies. Pharmacists are responsible for identifying patient symptoms that require further investigation of more serious conditions, as well as to offer appropriate referral advice. Direct consultation to pharmacists for OTC medication is anticipated to increase efficiency of health services at QP while enhancing the standard of patient care.

Potential barriers must be considered before this patient service can be successfully implemented. Individuals may not always recognize how pharmacists function or understand the part they play in assuring safe medication use. Qatar has a diverse population of medication users who conceivably possess different values and beliefs around drug therapy and pharmacist roles based on practices in their countries of origin. Most situations surrounding pharmacist selection of appropriate OTC medication require the acquisition and assessment of patient information; analysis regarding proper drug selection and use (including potential medical contraindications or precautions, adverse effects, drug interactions); and clinical judgment regarding suitability of drug therapy and when referral for further medical evaluation is advised. ${ }^{9}$ Heterogeneous patient groups in Qatar may not recognize the abilities of pharmacists to provide this care thereby averting a time-consuming medical office visit. Objectives of this study were to characterize the perceptions and use of non-prescription therapy in an ambulatory care patient population in Qatar and assess patient knowledge and comfort with pharmacist and nursing roles.

\section{Materials and methods}

This cross-sectional observational study involved development of a standardized, unvalidated four-item questionnaire orally administered by QP pharmacists in English and in Arabic. At the time of protocol development, no university institutional review board (IRB) was in place and so ethics approval was sought from an external (but local) body.

A convenience sample of patients having prescriptions processed at any of the four QP primary care medical clinics throughout Qatar during two separate 2-week periods (June 2008 and January 2009) were invited to participate. Every fifth patient presenting to the QP pharmacy site was systematically selected to interview. Individuals who did not give verbal informed consent or who were unable to answer the survey questions due to language barriers were excluded. The survey took approximately 5 minutes to conduct.

Between the two survey sampling periods, clinic nurses at one QP clinic were given authority to directly dispense certain OTC medications to patients during their triage assessment. As such, the second survey was amended to include four additional questions evaluating patient views on nursing knowledge and skills related to drug therapy according to a 5-point Likert scale.

Survey responses were further described according to pre-defined demographic parameters: 1) age; 2) gender; 3) country of origin; and 4) occupation. These variables have been studied in other self-medication research. ${ }^{1,2}$

Descriptive statistics were analyzed using SPSS for Windows standard version release 17.0 (SPSS Inc, Chicago, Illinois, USA). Categorical data is presented as percentages of frequency and continuous data reported as means with standard deviations. Comparisons between discrete patient variables defined a priori were performed using Chi-square test. All statistical tests were two-tailed and based on a significance level of alpha $<0.05$.

\section{Results and analysis}

During the four-week study period, 570 patients responded to the survey. The average age was 38.3 (SD 11.1) years and the majority were men $(92.1 \%)$ (Table 1). Twenty-nine countries 
Table I Patient survey respondent demographics

\begin{tabular}{ll}
\hline Gender (n, \% male) & $525(92.1)$ \\
Age, years (mean \pm SD) & $38.3($ II.I) \\
$<30$ years (\%) & $172(30.6)$ \\
$30-50$ years & $297(52.1)$ \\
$>50$ years & $93(16.3)$ \\
Country of origin (n, \%) & \\
Gulf Coast country (GCC) & $39(6.8)$ \\
Qatar alone & $34(5.9)$ \\
Bilad Al Sham & $31(5.4)$ \\
Africa & $67(11.8)$ \\
South East Asia & $310(54.4)$ \\
Asia & $107(18.6)$ \\
Europe & $12(2.1)$ \\
Other & $5(0.9)$ \\
Primary language (n, \%) & \\
Arabic & $129(22.6)$ \\
English & $37(6.5)$ \\
South East Asian dialects & $307(53.9)$ \\
Asian dialects & $95(16.7)$ \\
Other & $2(0.4)$ \\
\hline
\end{tabular}

Notes: Examples of countries represented in the categories include:South EastAsia - India, Nepal, Pakistan; Asia - Philippines, Korea; Gulf Coast - Qatar, Kuwait, Oman, Yemen; Bilad Al Sham - region including Syria, Jordan, Lebanon, Palestine territory.

were represented with over half (54\%) from South East Asian origins (India 37.9\%), followed by Asia (18\%), and Africa (11.8\%). Only 6.5\% and 22.6\% reported English or Arabic as their first language, respectively. Respondent characteristics and answers did not significantly differ between the June 2008 and January 2009 surveys periods.

When asked if they knew that some medical complaints could be assessed by a pharmacist, 87 (15.3\%) said "No" (Figure 1). One hundred twenty-five (21.9\%) were not aware that certain medications may be safely recommended by a pharmacist without having to see a physician; however, 486 $(85.3 \%)$ would be interested in such a pharmacist service. Patients described symptoms associated with cold and flu, pain (back, head, and stomach aches), allergy, and fever for which they would wish to seek therapy directly from the pharmacist (Table 2).

Eighty-percent of patients agreed with the statement that pharmacists give reliable advice about drugs compared with $38 \%$ who believed nurses give reliable medication advice $(P \leq 0.001)$. Seventy-six percent would be comfortable receiving medication directly from a pharmacist compared with $32 \%$ from a nurse $(P<0.001)$ (Table 3$)$.

Subgroup analysis according to occupation was abandoned due to incomplete data collection to satisfactorily categorize all respondents. Similarly, the small numbers of women precluded meaningful descriptions according to gender. Survey responses did not significantly vary when stratified according to age ( $<30$ years, $30-50$ years, $>50$ years). All ages of patients were more comfortable with advice and medication directly supplied by pharmacists, but those in the $30-50$ years age group expressed high rates of acceptability for nurses in these roles ( $46.6 \%$ and $44.4 \%$ ) compared with

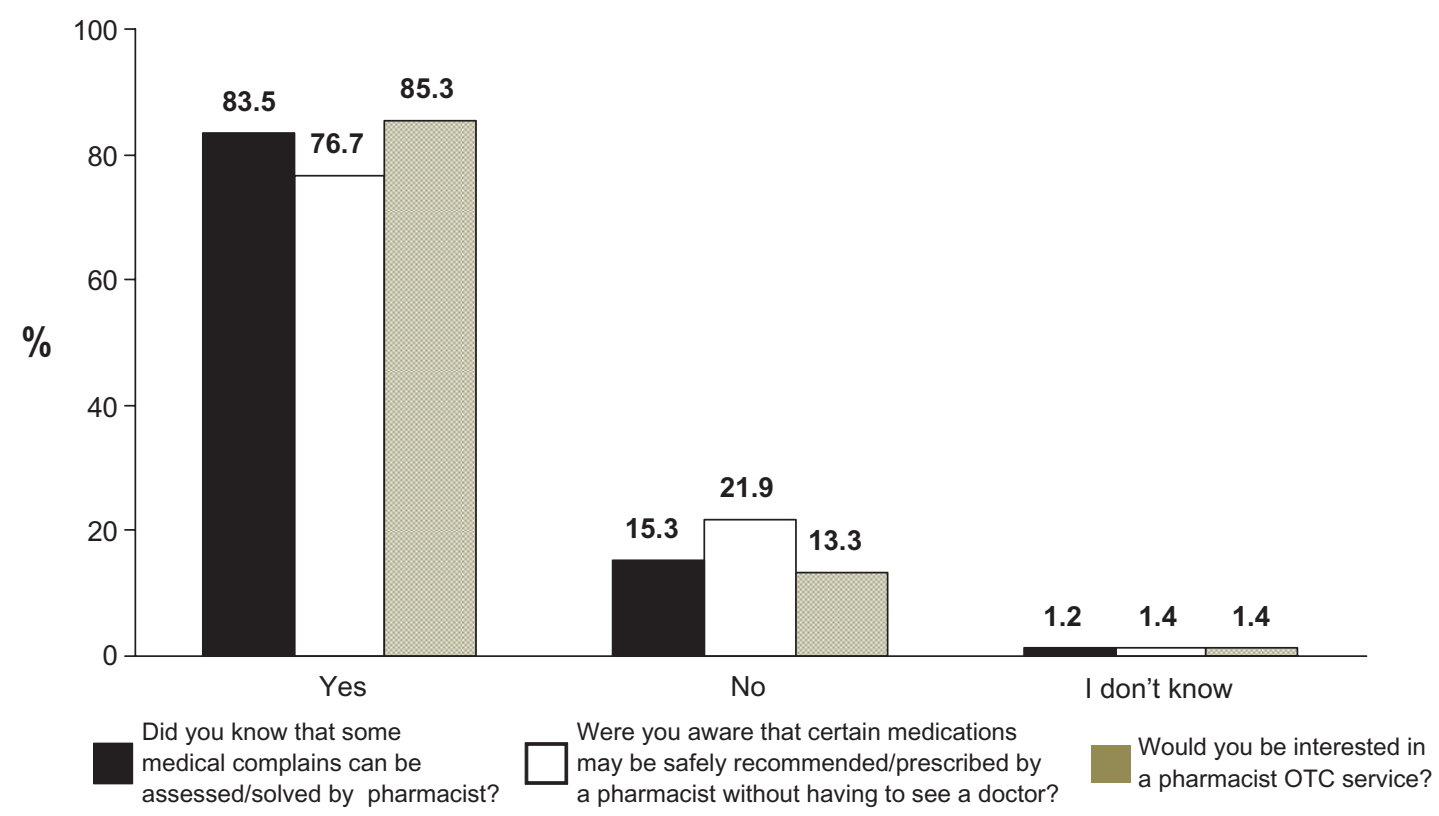

Figure I Patient survey question and responses. 
Table 2 Patient preferences for over-the-counter drug indications

\begin{tabular}{ll}
\hline Symptoms & Respondents (n, \%) \\
\hline Cold and flu & $302(52.9)$ \\
Pain & $237(41.6)$ \\
Headache & $125(21.9)$ \\
Gastrointestinal (dyspepsia, & $122(21.4)$ \\
constipation, diarrhea) & \\
Allergy & $91(16)$ \\
Fever & $63(11.1)$ \\
Vitamins (no specific indication) & $35(6.1)$ \\
Dry eye & $47(8.2)$ \\
Cutaneous (cuts, dermatologic & $31(5.4)$ \\
conditions, oral care) & \\
Patient's own prescription therapy & $3(0.5)$
\end{tabular}

Notes: $\mathrm{n}=570$. Individuals could offer more than one indication. $9.7 \%$ responded they were not interested in obtaining medication directly from a pharmacist. $14.8 \%$ of respondents did not offer any specific indication.

the younger $(30.5 \%$ and $41.6 \% ; P=0.15)$ and older cohorts (26.1\% and $30.4 \% ; P=0.09$ ). Individuals from Gulf Coast countries (GCC) were generally less aware of pharmacist abilities in patient assessment (66.7\%) and direct provision of medication (66.7\%) when compared with the overall average proportion of positive responses $(83.5 \%)(P=0.014)$ and $(76.7 \%)(P=0.22)$, respectively. However, $84.6 \%$ of these same respondents expressed high interest in using these services if made available. Corresponding proportions were only slightly higher for Qataris surveyed compared with the overall GCC group (70.6\% and 67.6\%, reported knowledge of pharmacist roles in patient assessment and direct provision of drug therapy, respectively and $88.2 \%$ would be interested in direct OTC access from a pharmacist). The proportion of respondents agreeable to pharmacist medication advice and direct supply of therapy ranged from $63.9 \%$ (Asian) to $100 \%$ (European) for each.

\section{Discussion}

Patients within this private ambulatory care setting were familiar with the roles of pharmacists as they pertain to selfmedication with OTCs. Although one-fifth was unaware that pharmacists could directly dispense specific drug therapy, the majority described the desire to use such a service if it were to become available within this health care practice. This implied rate of self-medication reflects patterns found elsewhere in the region. Forty-three percent of patients surveyed at community pharmacies in Jordan reported self-medication with OTC drugs, as did 58\% in a Saudi Arabia primary care clinic. ${ }^{1,3}$ Both populations described the perception of benign symptoms, and the prolonged time and increased cost of physician consultation as self-medication decision factors. In addition, it was found that individuals with higher literacy skills and minor perceived symptoms were more likely to self-medicate. $^{3}$

Intended OTC use by patients in our study was straightforward and consistent with usual safety and efficacy profiles accorded such therapy: medication intended to treat minor and self-limiting ailments for short periods of time. Self-medication for cough and cold symptoms, allergies, dyspepsia, and pain were also reported in other studies in the region. ${ }^{1-3}$ No patients in our study indicated the desire to specifically acquire antimicrobial therapies without a prescription, unlike $61.5 \%$ in one Jordan survey. ${ }^{3}$ The number wishing to access personal prescription therapies through self-selection (as they could in non-QP community pharmacies in Qatar) was also negligible. It is possible that these alternatives did not immediately come to mind to

Table 3 Patient survey responses

\begin{tabular}{llllll}
\hline Questionnaire item & Strongly agree & Agree & Neither agree or disagree & Disagree & Strongly disagree \\
\cline { 2 - 6 } & Responses, \%* & & 18.5 & 7 & 36.9 \\
\hline $\begin{array}{l}\text { A nurse gives reliable } \\
\text { advice about drugs }\end{array}$ & 19.1 & 18.5 & 13.4 & 1.3 & 5.7 \\
$\begin{array}{l}\text { A pharmacist gives reliable } \\
\text { advice about drugs }\end{array}$ & 54.1 & 25.5 & 15.2 & 16.6 \\
$\begin{array}{l}\text { I would be comfortable } \\
\text { receiving drugs directly } \\
\text { from a nurse }\end{array}$ & 40.8 & 10.8 & 16.6 & 1.9 & 6.4 \\
$\begin{array}{l}\text { I would be comfortable } \\
\text { receiving drugs directly } \\
\text { from a pharmacist }\end{array}$ & 54.1 & 22.3 & 15.3 & & \\
\hline
\end{tabular}

Notes: $*$ These questions were posed only in the second survey, $\mathrm{n}=171$. Respondents were asked to rate their level of agreement with the given statements. 
Qatar respondents when the survey question was posed in its open-ended manner.

Patients generally responded favourably when considering confidence in pharmacist knowledge and comfort with medication dispensing. While pharmacists enjoy a positive public image in a number of countries, very little is formally known about the views and attitudes in the region and virtually nothing in Qatar. ${ }^{10}$ Jordan has 8 established pharmacist-training programs and a pharmacist society (Jordanian Pharmaceutical Association) which may serve as vehicles for professional promotion and possibly correspond to favorable perceptions. Seventy-eight percent of the general public believed that pharmacists play an important role in the provision of advice regarding the safety and efficacy of OTC choices and 63\% would seek pharmacist advice for minor conditions. ${ }^{11}$ It is presently unknown whether the Qatar public possesses this high recognition of pharmacist roles in patient care and medication management.

Opinions pertaining to a nursing role in self-medication processes are not unlike those described elsewhere. ${ }^{12}$ Half of patients in our sample were not comfortable receiving drug therapy directly from a nurse, while a slightly lower proportion did not believe nurses to be reliable in providing drug information. However, not unlike pharmacists, nurses worldwide are adopting and extending roles for patient care and face similar obstacles from parties most familiar and comfortable with traditional professional boundaries. ${ }^{13}$ Qatar Petroleum health clinics are fashioned so that nurses are often the first point of contact for medical services. It is possible that as pharmacist OTC self-medication services are established and patient volume increases, an allied healthsupported (physician/pharmacist) OTC medication training program for nurses could be explored as a complementary, safe, and efficient means to triage self-medication patient needs at QP. ${ }^{14}$

The dearth of women respondents and incomplete patient profiles did not allow for intended exploration of patterns of responses according to gender or by occupation (as a surrogate marker of socioeconomic status). The lack of variation in knowledge and attitudes among different age groups could be attributed to the relative uniformity of our sample in regards to this demographic. Perceptions of pharmacists in direct patient care roles were somewhat lower among individuals from the GCC, including Qatar. Broadly speaking, current infrastructure and public policy to support community-based pharmacist activities beyond dispensing functions in the majority of these countries are still in their infancy. ${ }^{15}$ Professional efforts should be further stimulated by graduates from increasingly clinically-oriented programs who assume positions in Qatar and the region. ${ }^{16}$

Advancing pharmacist practice will increase expectations of QP staff. Increased workload is anticipated at QP pharmacies as more time will be required to engage patients in history-taking to ensure appropriate self-medication selection or physician referral for symptom evaluation. It is discouraging to note a body of evidence describing patient interactions where pharmacists provided insufficient or inaccurate medication or health information in practice settings across the world. ${ }^{17-19}$ Addressing inadequate competencies, training, and skills are among the top five global priorities for patient safety research in developing or transitional countries, such as Qatar. ${ }^{20}$ Knowledge and skills support through continuing education activities and technological tools will play an important roll for this and similar practice initiatives as pharmacists working in the country are a multi-national group emerging from heterogeneous curriculums and training programs abroad. ${ }^{16,21-23}$

A number of limitations to our survey warrant discussion. Qatar Petroleum pharmacists performed data collection as part of their usual patient dispensing interaction. Workload precluded ability to maintain complete records of the number of patients who declined or were ineligible to participate; therefore we do not have a total number of patients screened. While unfortunate, it is a realistic obstacle to ambulatory-based pharmacy practice research, particularly in novice settings in the absence of devoted research staff or compensation. ${ }^{24}$ Our short questionnaire was not formally evaluated for reliability and validity which is also a recognized barrier to the generalizability of the results, but is not inappropriate for the preliminary and exploratory nature of our study. ${ }^{25}$ Effort was made to avoid framing questions as direct comparisons between nurses and pharmacists, but potential response bias could not be avoided for the extended survey. Patients receiving health care from the pharmacist surveyor would be more likely to respond with favorable impressions of pharmacist drug knowledge and service. However, the fact that close to $10 \%$ did not feel that pharmacists offered reliable medication advice and were uncomfortable receiving drugs directly from them would indicate that not all respondents censored their true views.

Although two distinct survey time periods within a 6-month interval were chosen to minimize seasonal sampling error, potential subjects were drawn from a simple convenience sample, a nonprobabilty sampling approach that is appropriate during preliminary research efforts, but less robust than a randomization strategy. Electronic health data documented 24,000 distinct physician visits among all QP medical clinics during the sampling period. 
Our sample represents only a tiny fraction (2\%) and although data for total associated pharmacy visits during this same time frame is unavailable, our results may have limited generalizability to the entire QP patient population or indeed, ambulatory patients in the public system. No study of patient perceptions of pharmacist roles in public primary health care clinics has been reported, but a survey of patients visiting community pharmacies is underway (personal communication, M El Hajj, College of Pharmacy, Qatar University) with which comparisons may be drawn in the future. However, our subject demographics do mirror characteristics of the most recent population estimates in Qatar: official records place the population at 1.6 million of which 500,000 and 200,000 are from India and the Philllipines, respectively. ${ }^{26}$ The self-medication preferences of those patients unable to communicate with English and Arabic speaking pharmacists are not accounted for in our survey. Finally, women are grossly underrepresented in our sample. Some reasons include the high proportion of QP patients who are unaccompanied foreign male workers in the country or cultural factors involving male responsibility for family needs (such as medication procurement) or possible discomfort of female patients participating in a (potentially) male pharmacist-administered questionnaire. At the same time, the Qatar population is predominantly male (1.25 million vs 350,000 female). ${ }^{26}$ While is it unclear how age and gender may have influenced the awareness and attitudes towards pharmacist (or nurse) roles in guiding self-care in our sample population, other research reflects lower health consultations among males aged 5-74 years compared to females. ${ }^{27}$

Despite these factors, this study represents the first evaluation of patient perspectives on pharmacist roles and overthe-counter medication in Qatar. Research is underway at this site to characterize physician attitudes towards pharmacist activities. These findings will principally serve to inform the marketing of pharmacy services expansion to patients at QP, but will also contribute to a larger body of study regarding knowledge and attitudes towards pharmacist roles in the Middle East region. In this regard, future research should explore community practice, pharmacists who are arguably the most accessible and visible to the public, and the potential impact of pharmacist advocacy initiatives on levels of patient knowledge and expectations of pharmacist roles.

\section{Conclusion}

Patients in a private health care setting in Qatar demonstrated good awareness of pharmacist roles supporting patient self-medication. The majority of these patients was interested in such a service and generally expressed positive attitudes towards pharmacist provision of OTC medication and related advice. Direct provision of drug therapy from pharmacists was preferred over that by nurses. Future research should seek to evaluate an expanded sample of Qatar's population, notably in the public community pharmacy sector.

\section{Acknowledgments}

This publication was made possible by a grant from the Qatar National Research Fund under its Undergraduate Research Experience Program. Its contents are solely the responsibility of the authors and do not necessarily represent the official views of the Qatar National Research Fund.

\section{Disclosures}

The authors report no actual or perceived conflict of interest with this report.

\section{References}

1. Motassem-Al YM, Al-Bakri AG, Bustanji Y, Wasaify M. Self-medication patterns in Amman, Jordan. Pharm World Sci. 2008;30(1):24-30.

2. Abdelmoneim A, Al-Rabiy S, Abahussain E. Self-medication practices among diabetic patients in Kuwait. Med Princ Pract. 2008;17(4): 315-320.

3. Saeed AA. Self-medication among primary care patients in Farazdak Clinic in Riyadh. Soc Sci Med. 1988;27(3):287-289.

4. Hughes CM, McElnay JC, Fleming GF. Benefits and risks of self medication. Drug Saf. 2001;24(14):2664-2666.

5. Bradley CP, Bond C. Increasing the number of drugs available over the counter: arguments for and against. Br J Gen Pract. 1995;45(399): $553-556$

6. Kennedy JG. Over the counter drugs. Changing the role of doctors and pharmacists. BMJ. 1996;312(7031):593-594.

7. Hepler CD, Strand LM. Opportunities and responsibilities in pharmaceutical care. Am J Hosp Pharm. 1990;47(3):533-543.

8. Covington TR. Consumer value and professional opportunity in nonprescription drug therapy. Int J Pharm Edu. 2003;2(1):1-4.

9. Wertheimer AI, Serradell J. A discussion paper on self-care and its implications for pharmacists. Pharm World Sci. 2008;30(4):309-315.

10. The ratiopharm CFP Report on Pharmacy Services: Consumers' Perception of Pharmacy [online]. 2004; Accessed 1 Sep 2009. URL: http://www.ratiopharm.ca/display.asp?11 $=3 \& 12=24 \& \mathrm{~d}=24$

11. Wazaify M, Al-Bsoul-Younes S, Abu-Gharbieh E, Tahaineh L. Social perspectives on role of community pharmacists and OTC. Pharm World Sci. 2008;30(6):884-891.

12. Castle NG, Hanlon JT, Handler SM. Whom do older adults trust most to provide information about prescription drugs? Am J Geriatr Pharmacother. 2009;7(2):105-116.

13. Courtenay M. Nursing prescribing, policy, practice and evidence base. Br J Comm Nurs. 2008;13(12):563-566.

14. Hansford D, Gill D, McLaren J, Krska J. A training package for primary care nurses in conducting medication review: their views and the resultant outputs. J Clin Nurs. 2009;18(8):1096-1104.

15. Midha KK. President, International Pharmaceutical Federation. Keynote address. National Pharmacists Union Annual Meeting; 2008 Aug; Copenhagen, Denmark. Available from: http://www.fip.org/files/ fip/President $\% 20$ Speeches/Copenhagen, $\% 20$ Denmark, $\% 20$ NFU, $\% 20$ August_2008.pdf 
16. Kheir N, Zaidan M, Younes H, El Hajj M, Wilbur K, Jewesson P. Pharmacy education and practice in 13 middle eastern countries. Am JPharm Educ. 2008;72(1):1-13.

17. Vacca C, Orozco J, Figueras A, Capella D. Assessment of risks related to medicine dispensing by nonprofessionals in Colombia: clinical case simulations. Ann Pharmacother. 2005;39(3):527-532.

18. Alte D, Weitschies W, Ritter CA. Evaluation of consultation in community pharmacies with mystery shoppers. Ann Pharmacother. 2007;41(6):1023-1030.

19. Sallam SA, Khallafallah NM, Ibrahim NK, Okasha AO. Pharmacoepidemiological study of self-medication in adults attending pharmacies in Alexandria, Egypt. East Mediterr Health J. 2009;15(3):683-691.

20. Bates DW, Larizgoitia I, Prasopa-Plaizier N, Kjha A. Global priorities for patient safety research. BMJ. 2009;338(7704):1242-1244.

21. El Hajj M, Al-Zaidan MB, Kheir AN, Jewesson PJ. Medication use process in a Middle East country: results of the first national pharmacist opinion survey in Qatar. (Poster P15E). 2008 ASHP Midyear Clinical Meeting Dec 9, 2008. Orlando, Florida, USA.
22. Benmiroj SI, Werner JB, Raffaelel C, Roberts AS. A system for monitoring quality standards in provision of non-prescription medicines from Australian community pharmacies. Pharm World Sci. 2008;30(2):147-153.

23. Westerlund T, Andersson IL, Marklund B. The quality of self-care counseling by pharmacy practitioners, supported by IT-based clinical guidelines. Pharm World Sci. 2007;29(2):67-72.

24. Armour C, Brillant M, Krass I. Pharmacists' views on involvement in pharmacy practice research: Strategies for facilitating participation. Pharm Pract. 2007;5(2):59-66.

25. Scott I. You can't believe all that you're told: the issue of unvalidated questionnaires. Inj Prevent. 1997;3(1):5-6.

26. Qatar Statistics Authority [online]. 2009; Accessed 20 Nov 2009. URL: http://www.qsa.gov.qa/Eng/index.htm

27. Geoghegan T. BBC News Magazine. Why are men reluctant to seek medical help? [online]. 17 Jul 2009; Accessed 8 Jan 2010. URL: http:// news.bbc.co.uk/2/hi/uk_news/magazine/8154200.stm
Patient Preference and Adherence

\section{Publish your work in this journal}

Patient Preference and Adherence is an international, peer-reviewed, open access journal that focusing on the growing importance of patient preference and adherence throughout the therapeutic continuum. Patient satisfaction, acceptability, quality of life, compliance, persistence and their role in developing new therapeutic modalities and compounds to

\section{Dovepress}

optimize clinical outcomes for existing disease states are major areas of interest. This journal has been accepted for indexing on PubMed Central. The manuscript management system is completely online and includes a very quick and fair peer-review system. Visit http://www.dovepress.com/ testimonials.php to read real quotes from published authors. 